\title{
The Effect of Fertilizer Regime on Soil Fauna
}

\author{
Mignon SANDOR*, Traian BRAD, Aurel MAXIM, Valentina SANDOR, Bogdan ONICA \\ ${ }^{1}$ University of Agricultural Sciences and Veterinary Medicine Cluj-Napoca, Calea Mănă $\square$ tur 3-5, 400372, \\ Cluj-Napoca, Romania \\ ${ }^{2}$ Institute of Speleology Emil Racovita, Clinicilor 5, 400006 Cluj-Napoca, Romania \\ * corresponding author: sandor.mignon@usamvcluj.ro
}

Bulletin UASVM series Agriculture 73(2)/2016

Print ISSN 1843-5246; Electronic ISSN 1843-5386

DOI 10.15835/buasvmcn-agr: 12445

\begin{abstract}
Soil fauna activity in agricultural soil is a key factor to maintain soil fertility and to assure soil ecosystem services. It is now accepted that agricultural practices like tillage and pesticide use can harm soil organisms including earthworms and springtails. Other practices like the use of green manure or animal manure have been considered as being beneficial to these soil invertebrates. To deepen our knowledge on the effect of fertilizers (mineral and organic) on earthworms (Aporrectodea caliginosa and Lumbricus terrestris) and springtails (Folsomia candida) 56 microcosm experiments were made with two soil types and two hydric regimes. The microcosms were amended with four fertilizers: ammonium nitrate, mustard as green manure, cow manure and slurry. The results emphasize that mustard use had beneficial effect on Folsomia candida abundance and Aporrectodea caliginosa biomass, while mineral fertilizer had negative effects for all species used in the experiment.
\end{abstract}

Keywords: fertilization, soil, earthworms, springtails.

Introduction. Soil biotic community in arable agricultural fields provide multiple ecosystem services through their activity. Nutrient plant availability are directly related with complex relationship between soil microbiota and fauna. Wang et al. (2016) suggested that soil fauna could be a valuable indicator of soil fertility. Earthworms and collembolans are two faunal group which are able to be used as soil fertility indicators. The use of organic fertilizers in agricultural soil is associated with highest earthworm and collembolans activities (Whalen et al., 1998) while mineral fertilizers use is related with detrimental effects (Donahue, 2001; Riley et al., 2008) or with no effects (Deibert and Uther, 1994; Edwards and Lofty, 1982) on soil fauna.

Aims and objectives. The objective of the present study was to assess the influence of different fertilizers (mineral and organic) on two species of earthworms and one species of springtails.

Materials and methods. A number of 56 microcosms were set up in controlled condition.
Four types of fertilizers were applied: ammonium nitrate, mustard as green manure, cow manure and liquid manure. One treatment remains without any fertilizer as control. All microcosms except the control were inoculated with one individual of Lumbricus terrestris, one individual of Aporrectodea caliginosa and 200 individuals of Folsomia candida. After 30 days of incubation we recorded changes in earthworm wet biomass and collembolan density in all treatments.

Results and Discussion. During incubation period, the wet biomass of Lumbricus terrestris decreased in most treatments in both soils (Tab. 1). The decrease was more apparent in mineral treatments and in dry soil. The wet biomass of Aporrectodea caliginosa increased for most of the treatments. The increase was more evident in caw manure and mustard fertilized soils. In mineral fertilized soil Aporrectodea caliginosa registered a decrease of wet biomass. A significant increase of Folsomia candida abundance was observed in cow 
Tab. 1. Earthworms wet biomass and collembolans abundance (mean \pm S.E.)

\begin{tabular}{|c|c|c|c|c|c|c|c|c|c|}
\hline \multirow[b]{2}{*}{ Luvosoil soil } & & \multicolumn{2}{|c|}{$\begin{array}{l}\text { Liquid } \\
\text { manure }\end{array}$} & \multicolumn{2}{|c|}{$\begin{array}{c}\text { Cow } \\
\text { manure }\end{array}$} & \multicolumn{2}{|l|}{ Mustard } & \multicolumn{2}{|c|}{$\begin{array}{c}\text { Ammonium } \\
\text { nitrate }\end{array}$} \\
\hline & & wet & dry & wet & dry & wet & dry & wet & dry \\
\hline \multirow{3}{*}{$\begin{array}{l}\text { Aporrectodea } \\
\text { caliginosa } \\
\text { (g) }\end{array}$} & Start & $1.57 \pm 0.33$ & $0.83 \pm 0.07$ & $1.17 \pm 0.03$ & $0.87 \pm 0.03$ & $1.37 \pm 0.18$ & $0.73 \pm 0.03$ & $1.53 \pm 0.15$ & $0.77 \pm 0.09$ \\
\hline & End & $1.90 \pm 0.26$ & $1.07 \pm 0.09$ & $1.77 \pm 0.20$ & $1.70 \pm 0.06$ & $1.97 \pm 0.19$ & $0.85 \pm 0.12$ & $1.23 \pm 0.15$ & $0.95 \pm 0.04$ \\
\hline & Diff & $+21 \%$ & $+29 \%$ & $+51 \%$ & $+95 \%$ & $+44 \%$ & $+16 \%$ & $-19 \%$ & $+23 \%$ \\
\hline \multirow{3}{*}{$\begin{array}{l}\text { Lumbricus } \\
\text { terrestris } \\
\text { (g) }\end{array}$} & Start & $4.00 \pm 0.35$ & $2.53 \pm 0.15$ & $4.00 \pm 0.25$ & $2.87 \pm 0.09$ & $4.73 \pm 0.93$ & $2.80 \pm 0.23$ & $4.47 \pm 0.15$ & $3.20 \pm 0.36$ \\
\hline & End & $3.63 \pm 0.29$ & $1.93 \pm 0.20$ & $3.60 \pm 1.14$ & $2.63 \pm 0.23$ & $4.70 \pm 1.76$ & $2.90 \pm 0.00$ & $3.40 \pm 0.15$ & $2.30 \pm 0.00$ \\
\hline & Diff & $-9 \%$ & $-24 \%$ & $-10 \%$ & $-8 \%$ & $-1 \%$ & $+4 \%$ & $-24 \%$ & $-28 \%$ \\
\hline \multirow{2}{*}{$\begin{array}{l}\text { Folsomia } \\
\text { candida } \\
\text { (Ind) }\end{array}$} & End & $77 \pm 19$ & $296 \pm 70$ & $269 \pm 89$ & $341 \pm 47$ & $453 \pm 59$ & $71 \pm 7$ & $56 \pm 14$ & $137 \pm 20$ \\
\hline & Diff & $-62 \%$ & $+48 \%$ & $+35 \%$ & $+71 \%$ & $+127 \%$ & $-65 \%$ & $-72 \%$ & $-32 \%$ \\
\hline \multicolumn{2}{|c|}{ Chernozem soil } & wet & dry & wet & dry & wet & dry & wet & dry \\
\hline \multirow{3}{*}{$\begin{array}{l}\text { Aporrectodea } \\
\text { caliginosa } \\
\text { (g) }\end{array}$} & Start & $1.10 \pm 0.06$ & $0.67 \pm 0.07$ & $1.03 \pm 0.03$ & $0.60 \pm 0.00$ & $1.10 \pm 0.15$ & $0.63 \pm 0.03$ & $1.27 \pm 0.07$ & $0.80 \pm 0.06$ \\
\hline & End & $1.45 \pm 0.04$ & $1.10 \pm 0.08$ & $1.45 \pm 0.04$ & $1.30 \pm 0.06$ & $1.50 \pm 0.12$ & $1.27 \pm 0.09$ & $0.87 \pm 0.09$ & $0.70 \pm 0.08$ \\
\hline & Diff & $+32 \%$ & $+64 \%$ & $+41 \%$ & $+117 \%$ & $+36 \%$ & $+102 \%$ & $-32 \%$ & $-13 \%$ \\
\hline \multirow{3}{*}{$\begin{array}{l}\text { Lumbricus } \\
\text { terrestris } \\
(\mathrm{g})\end{array}$} & Start & $3.90 \pm 0.26$ & $2.40 \pm 0.26$ & $3.93 \pm 0.34$ & $2.40 \pm 0.21$ & $3.50 \pm 0.44$ & $2.13 \pm 0.09$ & $3.47 \pm 0.81$ & $1.97 \pm 0.57$ \\
\hline & End & $3.50 \pm 0.33$ & $2.47 \pm 0.26$ & $3.97 \pm 0.38$ & $3.03 \pm 0.27$ & $3.43 \pm 0.68$ & $1.80 \pm 0.49$ & $2.50 \pm 0.56$ & $1.65 \pm 0.37$ \\
\hline & Diff & $-10 \%$ & $+3 \%$ & $+1 \%$ & $+26 \%$ & $-2 \%$ & $-15 \%$ & $-28 \%$ & $-16 \%$ \\
\hline \multirow{2}{*}{$\begin{array}{l}\text { Folsomia } \\
\text { candida } \\
\text { (Ind) }\end{array}$} & End & $107 \pm 35$ & $147 \pm 30$ & $193 \pm 95$ & $631 \pm 111$ & $453 \pm 161$ & $231 \pm 17$ & $41 \pm 10$ & $112 \pm 24$ \\
\hline & Diff & $-47 \%$ & $-27 \%$ & $-4 \%$ & $+216 \%$ & $+127 \%$ & $+16 \%$ & $-79 \%$ & $-44 \%$ \\
\hline
\end{tabular}

manure and mustard fertilized treatments.

Conclusion. The type of fertilizers used in agricultural soils can be an important driver for soil biological community. While mineral fertilizers seem to have a detrimental impact on soil fauna, the use of caw manure and green manure showed beneficial effects in terms of biomass and density of soil invertebrates.

Acknowledgments. This work was supported by a grant of the Romanian National Authority for Science Research and Innovation, CNCS-UEFISCDI, project number PN-II-RU-TE-2014-4-2490.

\section{REFERENCES}

1. Deibert EJ, Utter RA (1994). Earthworm populations related to soil and fertilizer management practices. Better Crops, 78(3):9-11.
2. Donahue S (2001). Agricultural management effects on earthworm populations. Soil Quality-Agronomy Technical Note No, 11.

3. Edwards CA, Lofty JR (1982). Nitrogenous fertilizers and earthworm populations in agricultural soils. Soil Biology and Biochemistry, 14(5):515-521.

4. Wang S, Chen HY, Tan Y, Fan H, Ruan H (2016). Fertilizer regime impacts on abundance and diversity of soil fauna across a poplar plantation chronosequence in coastal Eastern China. Scientific reports, 6.

5. Whalen JK, Parmelee RW, Edwards CA (1998). Population dynamics of earthworm communities in corn agroecosystems receiving organic or inorganic fertilizer amendments. Biology and Fertility of Soils,27(4):400-407.

6. Riley H, Pommeresche R, Eltun R, Hansen S, Korsaeth A (2008). Soil structure, organic matter and earthworm activity in a comparison of cropping systems with contrasting tillage, rotations, fertilizer levels and manure use. Agriculture, Ecosystems \& Environment, 124(3):275284. 